\title{
Relação entre Lócus de Controle e resiliência de acordo com as características sociais dos estudantes de Contabilidade
}

\section{Resumo}

Objetivo: Analisar a relação do Lócus de Controle Interno e Externo com a resiliência, de acordo com as características sociais dos estudantes de Contabilidade.

Método: Os dados foram obtidos por meio de survey, utilizando-se as escalas de Levenson (1973) e Pesce, Assis, Avanci, Santos e Malaquias (2005) para Lócus de Controle e resiliência, respectivamente. A amostra corresponde a 449 estudantes de Contabilidade, de todas as regiões do Brasil, em que 31,63\% eram homens e 68,37\% mulheres. Para a análise dos dados foi realizada regressão linear múltipla, teste $\mathrm{T}$ de Student, teste ANOVA e Coeficiente Alfa, de Cronbach.

Resultados: Os resultados demonstram que estudantes de Contabilidade, de maneira geral, possuem altos níveis de resiliência, bem como de Lócus de Controle Interno, o que faz com que tenham um perfil de pessoas determinadas, autoconfiantes e perseverantes frente às dificuldades oferecidas durante o processo de formação no curso de graduação em Ciências Contábeis. Foram encontradas diferenças de níveis de Lócus de Controle e resiliência entre os sexos feminino e masculino, estudantes de instituições privadas, públicas e públicasprivadas e de acordo com o estado civil, sendo que os maiores níveis de Lócus de Controle Interno foram encontrados no sexo masculino, e a resiliência foi maior no sexo feminino. A resiliência não obteve diferença significativa de acordo com o estado civil dos estudantes, porém, o Lócus de Controle Externo foi maior percebido nos estudantes solteiros. Por fim, tanto o Lócus de Controle Externo quanto a resiliência foram maiores para estudantes de instituições públicas-privadas.

Contribuições: O estudo contribui ao identificar os níveis de resiliência e lócus de controle dos acadêmicos de Ciências Contábeis de acordo com gênero, estado civil, ou até mesmo com o tipo da instituição, fatores estes da teoria de aprendizagem psicológica e social, que possibilitam compreender os critérios que mais afetam as questões como a de permanência do curso.

Palavras-Chave: Lócus de Controle; Resiliência; Estudantes de Contabilidade.

\section{Juçara Haveroth}

https://orcid.org/0000-0001-7327-0667

Mestre em Ciências Contábeis pela Universidade Regional de Blumenau (Furb) e Doutoranda em Ciências Contábeis e Administração na Universidade Regional de Blumenau (Furb). Contato: Rua Antônio da Veiga, 140. Itoupava Seca. Blumenau (SC). CEP: 89030-903.

E-mail: jucara_haveroth@hotmail.com
Alyne Cecilia Serpa Ganz http://orcid.org/0000-0002-7192-6033
Mestre em Ciências Contábeis pela Universidade Regional de Blumenau (Furb) e Doutoranda em Métodos Quantitativos e Engenharia na Universidade Federal do Paraná (UFPR). Contato: Avenida Cel. Francisco Heráclito dos Santos, 210. Jardim das Américas. Curitiba (PR). CEP: 81531-980.
E-mail: alyneserpa@hotmail.com

\section{Ângela Bilk}

https://orcid.org/0000-0003-4321-854

Mestre em Ciências Contábeis pela Universidade Regional de Blumenau

(Furb). e Professora no Centro Universitário Leonardo da Vinci. Contato: Rodovia BR-470, 1.040. Benedito. Indaial (SC). CEP: 89130-000.

E-mail: angbilk07@gmail.com

\section{Marcia Zanievicz da Silva} https://orcid.org/0000-0003-1229-7705 Doutora em Ciências Contábeis e Administração pela Universidade Regional de Blumenau (FURB). E Professora do Programa de PósGraduação em Ciências Contábeis na Universidade Regional de Blumenau (FURB). Contato: Rua Antônio da Veiga, 140. Itoupava Seca. Blumenau (SC). CEP: 89030-903.

E-mail:marciaza@gmail.com 


\section{Introdução}

A contabilidade tradicional é comumente associada à responsabilidade pela elaboração e análise de demonstrações financeiras. No entanto, existem diversas outras informações no alcance da Contabilidade, não necessariamente de natureza financeira, que também devem ser consideradas e analisadas de modo a permitir o melhor auxílio aos usuários das informações. Nesse contexto, tem-se o campo de pesquisa na área de Contabilidade Comportamental, que considera a dimensão do comportamento humano aplicado à Contabilidade, sendo que engloba um conjunto de informações relevantes que devem (ou deveriam) ser analisadas pelos elaboradores das demonstrações contábeis (Lucena, Fernandes \& Silva, 2011).

A Contabilidade, como parte integrante das ciências sociais aplicadas, influencia os processos de tomada de decisão, destarte, também utiliza princípios comportamentais, oriundos da psicologia, para melhor compreender usuários e utilizadores das informações contábeis. Especificamente em relação à Contabilidade Comportamental, por se tratar de uma área que contempla diferentes perspectivas, autores como Siegel e Ramanauskas-Marconi, (1989) e Lucena et al. (2011) segregam as pesquisas em três áreas: i) construção e utilização do sistema de contabilidade; ii) efeito do sistema de contabilidade sobre o comportamento humano; iii) métodos de previsão e estratégias adotadas pelos usuários da contabilidade para alterar o comportamento humano.

No contexto da segunda perspectiva (efeito do sistema de contabilidade sobre o comportamento humano), Farag e Elias (2016) relatam que é importante compreender os estudantes de Contabilidade, por representarem a população de potenciais responsáveis pelas demonstrações contábeis, esses alunos estão se preparando para ser a próxima geração de contadores. Deste modo, escolher uma carreira na Contabilidade deve ser produto de uma reflexão e percepção do indivíduo quanto as suas características e personalidade, frente ao ambiente em que encontrarão na profissão escolhida (Magalhaes, 2005), embora existam outras razões subjacentes.

Ademais, a Contabilidade em si tem sido considerada como uma ocupação estressante, embora nem todo o estresse seja ruim (Selye, 1974), e ainda, as condições ambientais, tais como carga de trabalho, pressão de tempo e deveres conflitantes, no campo da Contabilidade, têm sido consistentes com este conceito de estresse (Hasin \& Omar, 2007). Portanto, pode ser favorável que exista uma relação entre a escolha da profissão e autoconhecimento, de modo que o indivíduo opte por carreiras que melhor representem a sua identidade pessoal, conjunto de interesses, habilidades e características de personalidade (Magalhães, 2005).

Desta forma, algumas variáveis comportamentais, como o Lócus de Controle e Resiliência têm sido foco de pesquisa em diversas áreas de conhecimento. No entanto, diferente de países da Europa e América do Norte, a temática no Brasil tem sido pouco investigada, especialmente quando aplicada em profissionais das áreas vinculadas às ciências sociais. Nesse sentido, compreende-se que a pesquisa sobre lócus de controle e resiliência no Brasil ainda é incipiente (Cowen, Wyman \& Work,1996; Yunes, 2003).

O lócus de controle corresponde à percepção de controle sobre a vida, determinada pelo próprio indivíduo, sendo um padrão de orientação (Rodrigues, 2007). Deste modo, existem dois parâmetros para o lócus de controle: interno e externo. Pessoas com Lócus de Controle Interno atribuem para si a responsabilidade, pelo o que lhes acontece, sentem-se responsáveis pelo controle da maior parte das situações que enfrentam e acreditam que podem interferir nos resultados destas situações (Dela Coleta, 1987; Callado, Gomes, Tavares, 2006). Enquanto pessoas com Lócus de Controle Externo tendem a atribuir a responsabilidade sobre o que lhes acontece aos outros ou ao que é externo, não se sentem capazes de controlar as situações pelas quais passam (Callado et al.,2006).

Por sua vez, na pesquisa assume-se que a resiliência consiste na capacidade humana para enfrentar e superar experiências de adversidade, possibilitando que o indivíduo saia fortalecido ou transformado (Yunes, Szymanski, 2001; Minello \& Scherer, 2014). Segundo Pesce, Assis, Santos e Oliveira (2004), a resiliência pode ser entendida como o conjunto de processos sociais e intrapsíquicos que possibilitam o desenvolvimento de uma vida sadia, mesmo vivendo em um ambiente não sadio. Os estudos e pesquisas sobre resiliência humana procuram compreender como algumas pessoas tem capacidade de desenvolvimento e superação melhor que outras, mesmo vivenciando as mesmas situações de adversidade, sendo que essas diferenças também podem ser proporcionadas pelo ambiente da graduação. 
Diante do exposto e considerando haver uma lacuna de pesquisa sobre a temática na Contabilidade, formula-se a seguinte questão de pesquisa: Qual a relação do lócus de controle interno e externo com a resiliência de acordo com as características sociais dos estudantes de Contabilidade? Com base na questão de pesquisa, o objetivo do estudo é analisar a relação do Lócus de Controle Interno e Externo com a resiliência de acordo com as características sociais dos estudantes de Contabilidade.

Para isso foi realizado um survey, utilizando as escalas de Levenson (1973) e Pesce, Assis, Avanci, Santos \& Malaquias (2005) para Lócus de Controle e resiliência, respectivamente. A amostra final compreende 449 estudantes de Contabilidade. A análise dos dados foi feita por meio de regressão linear múltipla, teste t de Student, ANOVA e Alfa de Cronbach. Os resultados demonstram que estudantes de Contabilidade, de maneira geral, possuem altos níveis de resiliência, bem como de lócus de controle interno, o que faz com que tenham um perfil de pessoas determinadas, autoconfiantes e perseverantes frente às dificuldades oferecidas durante o processo de formação no curso de graduação em Ciências Contábeis. Foram encontrados ainda maiores níveis de Lócus de Controle Interno em estudantes do sexo masculino, e resiliência maior para o sexo feminino. Tanto o Lócus de Controle Externo quanto a resiliência foram maiores para estudantes de instituições públicas-privadas.

A presente pesquisa se difere das demais uma vez que a resiliência é pouco estudada neste cenário, como tema central ou suas ligações, sendo que usualmente é relacionada a parte operacional (Cowen;Wyman; Work,1996; Angst, 2013). Ainda, autores das ciências sociais, como Yunes e Szymansky (2001); Barreira e Nakamura, (2006); Angst (2013) estudam o Lócus de Controle, porém, este como tema principal isolado. Desta forma, estudar estas relações em conjunto e ainda considerando as características sociais permite identificar os perfis dos acadêmicos de como estes reagem às situações, de acordo com seu nível de Lócus de Controle e resiliência. Esses achados podem auxiliar instituições e interessados na preparação dos indivíduos para o processo em que estão passando e minimizando os custos de traumas profissionais que poderiam desenvolver com possíveis falhas no processo de formação.

A pesquisa ainda complementa o estudo de Damascena, França e Silva (2016) que pesquisou somente a relação entre Lócus de Controle e resiliência com profissionais da área contábil, pesquisando acadêmicos e as subdivisões de Lócus de Controle e resiliência. Este estudo, portanto, se difere por estudar a relação de Lócus de Controle (interno, ao acaso e controle poderosos) com a resiliência (ações e valores, independência e determinação e autoconfiança e capacidade de adaptação às mudanças) de acordo com as características sociais, não identificada anteriormente.

O estudo de Lócus de Controle é importante, pois ajuda a compreender as características dos sujeitos com Lócus de Controle Interno e Externo, sendo que o tipo de Lócus de Controle impacta a resistência à coerção, influencia a capacidade de aceitar desafios e propicia maior persistência nos esforços para obtenção de resultados (Rodrigues, 2007), o que de fato é necessário para o indivíduo inserido em um ambiente acadêmico. Bem como, conforme apresentado pela teoria da Aprendizagem Social, de Rotter (1966), é preciso considerar a interação do sujeito com o ambiente, as variáveis de personalidade e as características individuais.

Quanto à contribuição para as pesquisas sobre resiliência, tem-se o aumento do interesse de pesquisa devido à necessidade de investimento em prevenção de problemas e promoção da saúde mental dos indivíduos em quaisquer que sejam as áreas de atuação (Pesce et al., 2004). No âmbito da educação, a resiliência desempenha um papel importante, porque há o favorecimento do desenvolvimento de habilidades sociais, acadêmicas e pessoais que permitem que o estudante supere as adversidades e tenha sucesso acadêmico, profissional e pessoal (Ruter,1987, Díaz, Giraldo, \& Buitrago, 2011).

Além de todas as contribuições teóricas apontadas sobre conhecer os efeitos das variáveis especificamente, a compreensão destas em conjunto traz contribuições práticas para as instituições de ensino. Destaca-se que estas podem se utilizar dos resultados dos seus acadêmicos de acordo com gênero, estado civil, ou até mesmo com o tipo da instituição, relacionadas ao nível de resiliência e lócus de controle, fatores estes da teoria de Aprendizagem Psicológica e Social (Lefcourt, 1976). Essas relações possibilitam compreender os critérios que mais afetam as questões como a de permanência do curso. 
Neste sentido, sugere-se que a discussão sobre estes critérios é de suma importância para as instituições de ensino superior que tem visto ano a ano o problema de evasão ser frequente e ainda incapaz de ser solucionada e completamente compreendida. A análise das variáveis individualmente permite traçar perfis que podem ser treinados e compreendidos para que a promoção de potencial dos acadêmicos possa ser maximizado.

O presente estudo ainda contribui para a literatura de educação em Contabilidade, pois enfatiza as relações existentes entre variáveis específicas de estudantes do curso, auxilia a identificar características de personalidade em uma população de futuros contadores, bem como amplia discussões sobre pesquisas que auxiliam os estudantes, para torná-los mais bem-sucedidos no futuro.

\section{Fundamentação Teórica}

Para fundamentar o presente estudo, o referencial teórico contempla a abordagem sobre Lócus de Controle, apresentando os conceitos, bem como aponta momentos em que o tema se relaciona com as ciências sociais e a Contabilidade. A mesma abordagem e desenvolvimento são realizados para os estudos de resiliência.

\subsection{Lócus de Controle}

Diferente do estudo de Damascena, França e Silva (2016), que objetivou analisar as relações e características entre o lócus de controle e a resiliência do profissional da contabilidade, quanto a seu posicionamento em relação às decisões da vida e o seu nível de resiliência, o presente estudo voltou à atenção aos acadêmicos de Contabilidade. Sabe-se que fazer um curso de graduação não é uma tarefa simples e, segundo Hasin e Omar (2007), o curso de Ciências Contábeis exige comprometimento do indivíduo e deve prepará-lo para atuar em uma profissão estressante, sendo, deste modo, importante conhecer e compreender o Lócus de Controle e a resiliência.

Rotter (1966) foi um dos primeiros autores a descrever o conceito de Lócus de Controle. Segundo esse autor, o Lócus de Controle refere-se à expectativa existente de nossos comportamentos em relação às contingências. Ainda segundo o autor, o constructo do Lócus de Controle é constituído de uma dimensão bipolar: de um lado do polo está a dimensão de internalidade e, no outro, a dimensão de externalidade. De acordo com esse constructo, as pessoas cujo Lócus de Controle é Interno (internalidade) acreditam que o alcance de seus objetivos depende de seus esforços e competências. Por sua vez, as pessoas com Lócus de Controle Externo (externalidade) creem que o alcance de seus objetivos depende de qualquer outro fator que não elas próprias, como, por exemplo, sorte, fé, destino, azar ou acaso.

Para Dela Coleta (1987), Lócus de Controle é uma variável que busca explicar uma característica relativa à percepção das pessoas sobre a fonte de controle dos acontecimentos ao qual são envolvidas. Segundo a autora, um indivíduo pode perceber-se como controlador destes acontecimentos ou como sendo os mesmos controlados por fatores externos a ele. Callado et al., (2006) contribuem com as discussões sobre o tema afirmando que as variáveis de personalidade e as características são consideradas individualmente, e estas não explicam o comportamento, pois é preciso considerar a interação do sujeito com o ambiente, e assim cada um demonstrará se é interno ou externo. Já para Rodrigues (2007), Lócus de Controle é a percepção de controle sobre a própria vida, ou seja, um padrão de orientação. Nas ciências sociais, autores como, Yunes e Szymansky (2001); Barreira e Nakamura, (2006); Angst (2013) e Damascena, França e Silva (2016) têm centrado atenção sobre a temática. 
Decorrente da multidimensionalidade do constructo de Lócus de Controle, surgiram diversas escalas para a mensuração desses fatores, assim como o consequente incremento dos estudos relacionados. Uma das principais contribuições propostas foi a realizada por Hanna Levenson, que dividiu a externalidade proposta por Rotter (1966) em duas, em que a sua versão de externalidade é dividida ao acaso e outros poderosos; o externo neste caso não deveria representar algo necessariamente ruim ou indesejável (Dela Coleta, 1987). Segundo Dela Coleta (1987), a escala de Levenson (1973) era semelhante à de Rotter (1966), teoricamente, mas, não, empiricamente.

Adaptada para o contexto brasileiro por Dela Coleta (1987) e validada por Tamayo (2012), escala de Levenson (1973) determina que as pessoas que depositam o controle em pessoas poderosas constituem os externos defensivos, os que percebem como fonte de controle o destino, a sorte, ou o azar, constituem os externos autênticos. E, por fim, pessoas que não acreditam no poder de outras pessoas, nem no acaso, destino ou sorte, mas em si próprios seriam os internos autênticos.

Em relação aos estudos de Lócus de Controle, de maneira geral pode-se dizer que eles descrevem várias características atribuídas aos sujeitos com orientação interna e externa. Conforme tais estudos, pessoas com lócus de internalidade são mais resistentes à coerção, engajam-se mais diretamente nas atividades para alcançar seus objetivos, aceitam mais os desafios, são mais persistentes e esforçados para obter resultados, resistentes à influência social, escolhem as situações à qual se submeter (Dela Coleta, 1982) -e estão associadas à maior ambição, motivação, sucesso na carreira profissional, aprendizagem no trabalho e desempenho organizacional (Macial \& Camargo, 2010).

Enquanto os externos manifestam mais emoções, sofrem mais influência afetiva, não assumem responsabilidade direta sobre os objetivos e são mais passíveis de influência persuasiva (Dela Coleta, 1982), além de serem associados a líderes com maior efetividade. Indivíduos que sustentam a crença de que o seu sucesso depende mais de fatores externos do que internos frequentemente apresentam maior consideração para com seus liderados.

Diante do exposto, compreende-se que o Lócus de Controle não é um conceito novo (Macial \& Camargo, 2010) para a pesquisa. Estudos de diversas disciplinas, tais como Psicologia, Administração, Recursos Humanos e Empreendedorismo, já realizaram pesquisas utilizando-se do constructo. Em relação a esses estudos, é possível perceber que o conceito tem passado por certa evolução no desenvolvimento de distintas medidas desde sua apresentação inicial, no entanto ainda existe uma lacuna de pesquisa quanto a determinadas áreas como é o caso da Contabilidade.

A Contabilidade tem seu berço enraizado nas ciências sociais aplicadas e, ao lidar com os processos de tomada de decisões, utiliza-se de princípios comportamentais, oriundos da Psicologia (Lucena et al., 2011). Partindo desse pressuposto, surge a oportunidade de pesquisa na Contabilidade Comportamental, envolvendo Lócus de Controle. Segundo MacDonald (1973), o desenvolvimento do Lócus de Controle pode ser afetado pela quantidade e qualidade das interações ambientais durante a infância, referentes à quantidade de controle que o indivíduo sente que obtém. , Este conceito também cabe ao se explicar a resiliência. Portanto, a próxima seção discute a resiliência que, em conjunto de lócus, compõe as variáveis estudadas nesta pesquisa.

\subsection{Resiliência}

A resiliência, diferente do Lócus de Controle, é um tema recente, que se encontra em fase de construção, discussão e debate. Por resiliência entende-se o conjunto de processos sociais e intrapsíquicos que possibilitam o desenvolvimento saudável do indivíduo, mesmo este vivenciando experiências desfavoráveis (Pesce et al., 2004). Segundo Oliveira, Reis, Zanelato e Neme (2008), o tema tem sido estudado por diferentes áreas do conhecimento. Antes de ser utilizado propriamente no campo das ciências humanas e sociais, o termo foi sugerido pelas ciências exatas para se referir à capacidade elástica de determinados materiais. 
Entretanto, a resiliência nos últimos anos passou a aparecer com mais frequência na literatura. Devido à tal atenção, pesquisas sobre este tema cresceram e a maioria destas utilizam definições com foco operacional (Cowen, Wyman; Work, 1996). O crescente interesse pelo conceito de resiliência nas ciências sociais e humanas são reflexos da necessidade do investimento em prevenção de problemas e promoção da saúde mental dos seres humanos (Pesce et al., 2004).

O contemporâneo movimento pela promoção da saúde tem revelado a resiliência como um conceito importante nessa área de conhecimento (Pesce et al., 2004). Os estudos e pesquisas sobre resiliência humana procuram compreender como algumas pessoas adquirem capacidade de superação melhor que outras, mesmo vivenciando situações similares de adversidade (Minello \& Scherer, 2014). Nesse sentido, a resiliência não é um atributo de nascença, ou adquirido no seu desenvolvimento, mas um processo interativo entre elas e seu meio (Rutter, 2012).

De forma geral, algumas definições de resiliência foram moldadas ao longo do tempo. Para Yunes (2003), resiliência se refere à habilidade de superar adversidades, o que não significa que não ocorram mudanças nos indivíduos, como sugerem os termos invulnerabilidade e invencibilidade. De acordo com Fortes, Portuguez e Argimon (2009), a resiliência é definida como a capacidade do indivíduo ou da família de enfrentar as adversidades, ser transformado por elas e conseguir superá-las.

Identifica-se que a resiliência possui várias definições. As pessoas e grupos diferem quanto às suas sensibilidades e vulnerabilidades diante de certos tipos de eventos, bem como em suas interpretações e reações, e isso parece estimular o desenvolvimento de pesquisas para mensurar a resiliência. As pesquisas sobre resiliência como tema central ou associado a outros aspectos são poucas e caracterizam a lacuna para a realização desta pesquisa, pois segundo Angst (2013) o termo não tem sido aplicado nas ciências sociais.

Nesse sentido, na análise das abordagens e descobertas sobre o conceito de resiliência, Grotberg (2003) identificou oito aspectos que representam os achados, sendo que destes destaca-se: a ligação das fases do desenvolvimento e crescimento humano, incluindo diferenças de idade e gênero, a sua possibilidade de mensuração, a participação na saúde mental e qualidade de vida. A prevenção e promoção são alguns dos conceitos a respeito da resiliência que é um processo: há fatores de resiliência, comportamentos resilientes e resultados resilientes.

No contexto do trabalho, a resiliência explica a mobilização de recursos psicossociais para o enfrentamento das rupturas e situações de tensão características da modernidade (Rogge \& Lourenço,2015). Destaca-se que não há consenso quanto ao número de eventos de vida negativos necessários para afetar a capacidade de resiliência do indivíduo (Pesce et al., 2004). Os diferentes níveis individuais de tolerância ao estresse também oscilam conforme o período de vida em que o evento ocorre e conforme a situação é enfrentada: uma pessoa é perturbada por pequenas mudanças, algumas são afetadas por eventos de maior magnitude, outras quando a exposição ao evento é mais prolongada ou ainda algumas podem alcançar seu limite de tolerância apenas com o acúmulo de pequenos eventos estressantes do dia a dia (Savoia, 1999).

Para Díaz et al. (2011), é a combinação entre a natureza, a quantidade e a intensidade dos fatores de risco o que define o contexto da adversidade necessária para a resiliência. No âmbito da educação, a resiliência desempenha um papel importante, porque por intermédio de seu desenvolvimento, é possível ocorrer o favorecimento do desenvolvimento de habilidades sociais, acadêmicas e pessoais que permitam que o aluno supere as adversidades e tenha sucesso na vida (Rutter, 1987).Nesse sentido, e com o intuito de ampliar os estudos sobre o desempenho acadêmico, inclusive nos aspectos de evasão, a pesquisa centra atenção na discussão relativa aos aspectos de Lócus de Controle, características pessoais e a resiliência, de maneira a identificar a percepção dos acadêmicos de Ciências Contábeis em tais aspectos. 


\subsection{Características sociais e desenvolvimento das hipóteses}

A cada ano que passa, adquirem-se novas oportunidades de refletir sobre os eventos científicos que determinam nosso conhecimento sobre o melhor entendimento de todas as pessoas. Assim, a importância de promover o potencial de todos, tem ganhado foco e, consequentemente realçado a importância do conceito de resiliência (Infante, 2005). No âmbito da educação, a resiliência desempenha um papel importante, porque por meio da promoção pode favorecer o desenvolvimento de habilidades sociais, acadêmicas e pessoais que permitem o aluno superar as adversidades e ter sucesso na vida (Ruter, 1987).

No entanto, as pesquisas sobre a resiliência de estudantes, especialmente considerando o ensino superior, têm sido escassas. Embora, algumas tentativas voltem olhares ao desempenho acadêmico e busquem $\mathrm{o}$ analisar, se tem focado em sua multidimensionalidade, tentando discutir variáveis familiares sociais e de educação que podem afetar sua condição, porém, pouco se evidencia as informações sobre características sociais (Díaz, Giraldo \& Buitrago, 2011). Isso indica que há poucos estudos que busquem compreender o desempenho acadêmico de forma mais aprofundada.

O problema é instaurado quando se identifica que o mau desempenho é um dos principais e mais comuns problemas nas universidades, que pode levar o aluno a se evadir do curso (Díaz, Giraldo \& Buitrago, 2011), isso porque a evasão no âmbito da graduação é uma preocupação recorrente em qualquer Instituição de Ensino Superior (Cunha; Nascimento \& Durso, 2014). Apesar de as características socioeconômicas e culturais serem distintas entre as diferentes instituições (públicas ou privadas), alguns estudos apontam características semelhantes desse fenômeno; uma delas se refere às percepções individuais de cada indivíduo.

A fim de auxiliar na redução desta lacuna, esta pesquisa utiliza fatores chamados de características sociais de estudantes, como sexo, estado civil e instituição de ensino frequentada, que devem ser analisados em situações de risco acadêmico, como, por exemplo, a frustração profissional que acompanhará um discente por toda a vida por começar e não terminar um curso de graduação (Cunha, Nascismento \& Durso, 2014). Sendo interferentes nestes aspectos de interação com o ambiente e percepção dos acontecimentos em sua vida, tem-se o Lócus de Controle e a resiliência.

O Lócus de Controle é considerado uma característica derivada da percepção dos indivíduos sobre o comando das ocorrências e situações aos quais são submetidos (Dela Coleta, 1987). A percepção quanto à distribuição do comando pode ser quanto ao autocomando ou quanto ao comando por fatores externos e sem capacidade de alteração por parte do indivíduo. Ao passo de que a resiliência é entendida como um aglomerado de experiências e processos sociais e intrapsíquicos que auxiliam o desenvolver do indivíduo, independentemente da procedência das experiências vivenciadas (Pesce et al., 2004).

Para Callado et al., (2006) as discussões individuais como personalidade e características não devem ser investigadas de forma solitária, por que podem ser decorrentes de interações com o ambiente ao qual estão imersas, e desta forma ter-se-á a concepção se essas características quanto ao comando são internas ou externas/submetidas. O estudo do ambiente em que os indivíduos estão inseridos é de grande importância por esse influenciar seu comportamento e contribuir para com a formação de características e personalidade. Neste sentido, Minello e Scherer (2014) afirmam que mesmo vivenciando experiências similares de dificuldades e infortúnios, há indivíduos que adquirem maiores habilidades e capacidade de superação do que outros, e isto pode ser estudado por meio de pesquisas sobre resiliência.

Assim, a resiliência não é caracterizada como pronta, ou de posse de certo indivíduo e, sim, como construída/desenvolvida de acordo com o processo interativo entre esse e seu meio (Rutter, 2012). Logo, o Lócus de Controle sendo entendido como um padrão do indivíduo, que age como reconhecedor das razões dos acontecimentos da sua vida (Rodrigues, 2007) e a resiliência a capacidade de enfrentar adversidades, sofrer mudanças por essas e conseguir a superação (Fortes, Portuguez \& Argimon, 2009), pressupõe-se uma relação entre as temáticas uma vez que dependendo de como o indivíduo perceba o controle das situações vivenciadas na sua vida, diferente será sua reação a ele e, portanto, a sua capacidade de resiliência e superação. 
Sendo o Lócus de Controle Interno (LCI), Lócus de Controle ao Acaso (LCC) e Lócus de Controle Poderosos (LCP) diferentes percepções sobre quem é o responsável pelas situações adversas enfrentadas cotidianamente pelo indivíduo, ressalta-se que essas diferentes percepções irão impactar diferentemente a resiliência, uma vez que os julgamentos e sofrimentos derivativos de situações indesejáveis e infortunas permitem ao indivíduo reconhecer, desenvolver e mobilizar recursos e habilidades em si mesmo que podem antes nunca se ter feito notar (Calvo \& Garcia, 2010). Isto é confirmado por Rodrigues (2007), que afirma que, além de influenciar nas estratégias de vida, o Lócus de Controle também influencia como as pessoas se comportam e planejam seus atos baseadas em suas ações e resultados.

Ainda, Damascena et al. (2016) encontra em seu estudo com profissionais da área de Contabilidade uma relação direta e significante entre o Lócus de Controle e a resiliência. Diante de todo o exposto, desenvolveu-se as seguintes hipóteses de pesquisa:

- H1: A resiliência de estudantes contábeis possui relação com o Lócus de Controle.

- H2: As características sociais discriminam a resiliência e o Lócus de Controle dos estudantes de Contabilidade.

\section{Procedimentos Metodológicos}

Com o propósito de atender o objetivo de analisar a relação do Lócus de Controle Interno e Externo com a resiliência de acordo com as características sociais dos estudantes de Contabilidade, foi realizada uma pesquisa quantitativa com coleta de dados por questionário. A população da pesquisa compreende alunos do curso de Ciências Contábeis de todas as fases, e de todas as regiões do Brasil que responderam a survey encaminhada por e-mail de forma individual. Os dados referentes à população foram alcançados realizando buscas nas instituições de ensino superior tanto pública como privada que ofertavam o curso de Ciências Contábeis na sua instituição. O questionário foi repassado para os participantes por link do google docs, resultando em 449 respostas que compõe a amostra estudada.

O instrumento utilizado para a coleta de dados foi um questionário composto de três etapas. A primeira etapa corresponde aos dados demográficos dos respondentes, que nesta pesquisa recebe o nome de dados sociais. A segunda etapa corresponde à escala de Lócus de Controle, sendo a utilizada à versão de Levenson (1973) que mensura, o Lócus de Controle em três partes, sendo LCI - Lócus de Controle Interno, LCC- Lócus de Controle ao Acaso e LCP - Lócus de Controle Poderosos. Por fim, a última etapa corresponde a escala de resiliência de Pesce, Assis, Avanci, Santos \& Malaquias (2005) que classifica a resiliência em três fatores distintos, neste caso chamados de fatores I, II e III. Ambas as escalas são discutidas na próxima seção. $O$ constructo referente ao questionário é apresentado na Tabela 1.

Tabela 1

\section{Constructo do Questionário}

\begin{tabular}{|c|c|c|c|}
\hline Variáveis & Descrição & Bloco & Questões \\
\hline Características Sociais & - & 1 & 1 a 10 \\
\hline \multirow{3}{*}{ Lócus de Controle } & $\mathrm{LCl}$ & \multirow{3}{*}{2} & $1,4,5,9,18,19,21,23$ \\
\hline & LCC & & $2,6,7,10,12,14,16,24$ \\
\hline & LCP & & $3,8,11,13,15,17,20,22$ \\
\hline \multirow{3}{*}{ Resiliência } & Fator I & \multirow{3}{*}{3} & $1,2,6,8,10,12,14,16,18,19,21,23,24,25$ \\
\hline & Fator II & & $5,7,9,11,13,22$ \\
\hline & Fator III & & $3,4,15,17,20$ \\
\hline
\end{tabular}

Fonte: dados da Pesquisa. 
Após a coleta de dados, verificaram-se os métodos estatísticos a serem utilizados, optando-se pela estatística descritiva, regressão linear múltipla, teste T de Student, teste ANOVA e Coeficiente Alfa de Cronbach para análise de confiabilidade dos dados. A estatística descritiva é utilizada para compreender o comportamento de uma variável no conjunto de dados sob análise1. O teste t de Student e ANOVA são testes paramétricos para comparação de médias e foram usados para discriminação das médias de resiliência e Lócus de Controle quanto as características dos estudantes de Contabilidade. O teste t compara médias de forma binária e, segundo Hair, Black, Babin, Anderson e Tatham (2009), é utilizado para amostras quando não se conhece a variância populacional e se tem por objetivo testar se uma média assume, ou não, determinado valor.

O teste ANOVA compara médias de amostras maiores, sendo considerado uma extensão do teste t e é aplicado quando busca-se testar se as médias das populações são iguais (Hair et al. 2009). Para que a hipótese nula de que os dados são iguais seja rejeitada precisa existir pelo menos um grupo de médias diferente dos demais. No ANOVA assume-se que cada grupo provém de uma distribuição normal com médias e com variância homogênea. A normalidade dos dados foi assumida de acordo com o teorema do limite central, devido ao tamanho da amostra.

Para o desenvolvimento da pesquisa, foram realizadas também regressões, sendo estas lineares múltiplas. De acordo com Fávero, Belfiore, Silva e Chan (2009), a regressão linear tem por objetivo estudar a relação entre duas ou mais variáveis explicativas, apresentando uma relação com uma variável dependente métrica. As equações que demonstram os modelos de regressão utilizados neste estudo são representadas pelas equações a seguir, a iniciar pela regressão linear múltipla dada pela equação (1).

$$
\begin{gathered}
R F I=\beta_{0}+\beta_{1} L C I+\beta_{2} L C C+\beta_{3} L C P+\varepsilon \\
R F I I=\beta_{0}+\beta_{1} L C I+\beta_{2} L C C+\beta_{3} L C P+\varepsilon \\
R F I I I=\beta_{0}+\beta_{1} L C I+\beta_{2} L C C+\beta_{3} L C P+\varepsilon \\
R E S I L=\beta_{0}+\beta_{1} L C I+\beta_{2} L C C+\beta_{3} L C P+\varepsilon
\end{gathered}
$$

Onde RFI é referente ao Fator I de Resiliência, é referente ao Fator II de Resiliência, é referente ao Fator III de Resiliência, é referente à Resiliência de modo geral, LCI é referente ao Lócus de Controle Interno, LCC é referente ao Lócus de Controle ao Acaso, LCP é referente ao Lócus de Controle Poderosos, é o erro aleatório da regressão e são coeficientes gerados pela regressão, que expressam a sensibilidade da resiliência quanto às variáveis independentes. Por fim, é realizada a análise de confiabilidade dos dados que permite analisar a escala de mensuração utilizada na pesquisa, assim fornecendo informações sobre as relações entre os seis itens individuais dela, conduzindo a validação dos mesmos seis traços.

De forma específica, a estatística descritiva foi realizada com a intenção de descrever os dados utilizados na pesquisa, explanar o percentual de respondentes femininos e masculinos e os níveis médios de lócus e resiliência apresentados por eles. A regressão linear múltipla estimada pelos Mínimos Quadrados Ordinários (MQO) foi feita com o objetivo de diagnosticar a relação do Lócus de Controle com a resiliência.

O teste T de Student foi utilizado para testar se há diferença entre os níveis de Lócus de Controle e resiliência entre respondentes do sexo feminino e masculino. O teste ANOVA por sua vez explora a diferença de Lócus de Controle e resiliência entre os respondentes de instituições públicas, privadas e públicas-privadas, e também entre respondentes solteiros, casados e viúvos. Por fim, o Alfa de Cronbach comprova a validade dos respondentes para com a pesquisa. O desenvolvimento das escalas utilizadas é explanado de forma mais detalhada no próximo tópico. 


\subsection{Escalas de Lócus de Controle e resiliência}

A escala de Lócus de Controle foi proposta por Rotter (1966), que inicialmente desenvolveu uma teoria de aprendizagem social na qual postulava que a tendência a realizar algum comportamento é, em parte, função da expectativa de que a resposta será seguida de reforço. Rotter (1966) define Lócus de Controle como a expectativa generalizada de alguém em sua capacidade de controlar os acontecimentos que seguem as suas ações. Propôs uma divisão em dois grupos Lócus de Controle Interno (LCI) e Lócus de Controle Externo (LCE), em que o LCI corresponde à quando o indivíduo percebe os resultados como consequência de suas ações e o LCE corresponde à percepção dos resultados como consequência de fatores externos.

No entanto, Levenson (1973), ao estudar a teoria de Rotter, sugeriu a divisão da dimensão externalidade em duas subdimensões: atribuição ao acaso e atribuição a outros poderosos. De acordo com a pesquisadora, a externalidade não é uma dimensão negativa como se acreditava pela versão de Rotter. Levenson (1973) sugeriu os "externos defensivos" que vislumbram a possibilidade de haver algum controle pessoal no futuro, porém, determinam a consequência pelo que ela nomeou de poderosos. E os externos, similar ao proposto por Rotter (1966), percebem como a fonte de controle o destino, a sorte, ou o azar; estes constituem os "externos autênticos".

A escala multidimensional de Levenson (1973) foi adaptada para o contexto brasileiro por Dela Coleta (1987) e validada por Tamayo (2012). De maneira geral, na divisão proposta por Levenson (1973) existem três tipos de orientações: $1^{\text {a }}$ Internos Autênticos (internalidade) - pessoas que não acreditam no poder de outras pessoas, nem no acaso, destino ou sorte, mas em si próprios; $2^{\mathrm{a}}$ Externos Defensivos (poderosos) - pessoas que acreditam no poder de outras pessoas, mas não acreditam no azar e nem em si

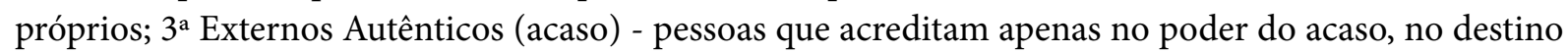
ou na sorte, ou seja, não acreditam no seu próprio poder ou no poder de outras pessoas.

A escala é composta por 24 itens divididos em três subdimensões com oito assertivas cada uma: Lócus de Controle Interno (LCI), Lócus de Controle Outros Poderosos (LCP) e Lócus de Controle ao Acaso (LCC). Lendo os itens que compõem as três subescalas da escala multifatorial de Lócus de Controle, determina-se que escores maiores na subescala de "internalidade" indicam crença em si mesmo; maiores escores na subescala "outros poderosos" indicam crença em pessoas poderosas; e maiores escores na subescalas "acaso" apontam para crença no acaso. A escala é do tipo likert de cinco pontos, e os respondentes escolheram uma opção entre "Discordo totalmente" até "Concordo totalmente". Assim como no estudo de Damascena et al. (2016) utilizou-se do critério para definição do nível do Lócus de Controle: 4,20 a 5,00 - nível muito alto; 3,40 a 4,19 - nível alto; 2,60 a 3,39 - nível neutro; 1,80 a 2,59 - nível baixo; e 1,00 a 1,79 - nível muito baixo. Este estudo também confirmou sua confiabilidade por meio do Alfa de Cronbach representando um nível de 0,790 .

Quanto à escala de resiliência, Wagnild e Young (1993), realizaram a primeira validação que possuía dois fatores a serem analisados, sendo o fator I denominado "competência pessoal", e o fator II, "aceitação de si mesmo e da vida”. Após a adaptação, Pesce et al. (2005) abdicaram da classificação original, optando por dividir a escala de Resiliência em três fatores: Fator I - composto por 14 assertivas que indicam resolução de ações e valores (que dão sentido à vida, como amizade, realização pessoal, satisfação e significado da vida); Fator II - com seis assertivas, que transmitem ideia de independência e determinação e Fator III - composto de cinco assertivas, que apresentam indicativos de autoconfiança e capacidade de adaptação a mudanças. Para calcular os escores da escala de resiliência, foi aplicada a mesma lógica utilizada para análise da escala multifatorial de Lócus de Controle. Também foi confirmada a confiabilidade por meio do Alfa de Cronbach representando um nível de 0,856.

Com base nos dados coletados, realizaram-se os procedimentos de análise, os quais tiveram por embasamento as variáveis estimadas de acordo com a Tabela 2, que apresenta de forma sucinta o constructo utilizado na pesquisa. 
Tabela 2

\section{Constructo das variáveis da pesquisa}

\begin{tabular}{|c|c|c|}
\hline Tipo da Variável & Variável & Mensuração \\
\hline \multirow{3}{*}{ Dependente } & RFI & Média da Resiliência das questões que compõe o fator I (Ações e valores) \\
\hline & RFII & $\begin{array}{l}\text { Média da Resiliência das questões do fator II (Independência e } \\
\text { determinação) }\end{array}$ \\
\hline & RFIII & $\begin{array}{l}\text { Média da Resiliência das questões do fator III (Autoconfiança e } \\
\text { capacidade de adaptação às mudanças) }\end{array}$ \\
\hline \multirow{6}{*}{ Independente } & $\mathrm{LCl}$ & Média das questões de Lócus de Controle Interno \\
\hline & LCC & Média das questões de Lócus de Controle ao Acaso \\
\hline & LCP & Média das questões de Lócus de Controle Poderosos \\
\hline & SEXO & Assume 0 quando masculino e 1 quando feminino \\
\hline & Estado Civil & Assume 0 quando solteiro; 1 quando casado e 2 quando viúvo. \\
\hline & IES & Assume 0 quando pública; 1 quando privada e 2 quando Pública/Privada \\
\hline
\end{tabular}

Fonte: elaborado pelas autoras.

Na Tabela 2 são explanados os três fatores de resiliência que compreendem a variável dependente e as variáveis referentes ao Lócus de Controle e as características sociais (dummies) que são as variáveis independentes. Os testes estatísticos analisados foram efetuados por meio do software SPSS 21.0.

\section{Análise dos Dados}

Nesta seção são discutidos os resultados do estudo. As estatísticas descritivas das variáveis estão apresentadas na Tabela 3.

Tabela 3

Estatísticas descritivas das variáveis utilizadas na pesquisa

\begin{tabular}{cccccccc}
\hline Variável & Frequência & LCI & LCC & LCP & RFI & RFII & RFIII \\
\hline \multirow{2}{*}{ Masculino } & \multirow{2}{*}{142} & 3,66 & 2,39 & 2,42 & 3,92 & 3,26 & 3,78 \\
& & $(0,43)$ & $(0,66)$ & $(0,62)$ & $(0,44)$ & $(0,45)$ & $(0,52)$ \\
\hline \multirow{2}{*}{ Feminino } & \multirow{2}{*}{307} & 3,65 & 2,44 & 2,26 & 4,01 & 3,34 & 3,89 \\
& & $(0,44)$ & $(0,52)$ & $(0,56)$ & $(0,43)$ & $(0,44)$ & $(0,47)$ \\
\hline
\end{tabular}

Legenda: As informações sobre médias aparecem sozinhas no texto, enquanto as informações entre parênteses são referentes ao desvio-padrão.

Fonte: dados da Pesquisa

Na Tabela 3, observam-se as variáveis de Lócus de Controle, resiliência e sexo. A começar pela análise de Lócus de Controle, identifica-se que tanto homens $(3,66)$ como mulheres $(3,65)$ atribuem um nível alto ao Lócus de Controle Interno (LCI), o que determina que os respondentes, em média, citam-se como responsáveis pelos acontecimentos da sua vida. Neste caso, pode-se identificar um perfil dos estudantes como internos autênticos. Esses resultados são particularmente importantes, considerando o ambiente acadêmico, visto que indivíduos com Lócus de Controle Interno buscam engajar-se nas atividades que remetem a suas capacidades de alcançar seus objetivos, e são mais persistentes e esforçados para obterem resultados (Dela Coleta, 1982), estando associadas à maior ambição, motivação, sucesso na carreira profissional (Macial \& Camargo, 2010), o que configura uma característica importante para graduandos. 
De forma geral, as variáveis de Lócus de Controle foram, em média, semelhantes para homens e mulheres respondentes da pesquisa, apesar de ser de conhecimento geral que estes têm personalidades e características diferentes, isso não explica seu comportamento, pois é preciso considerar a interação com o ambiente (Callado et.al, 2006). Identificou-se, portanto que os homens, além de apresentarem maiores Lócus de Controle Interno, também são os que mais determinam aos poderosos (LCP-2,42) os acontecimentos das suas vidas, antes de considerar a fatores externos de acaso (LCC-2,39). Sujeitos com Lócus de Controle Interno mais elevados engajam-se mais diretamente nas atividades para alcançar seus objetivos, enquanto que os externos manifestam mais emoções de não responsabilidade direta (Levenson, 1973; Dela Coleta, 1987).

Analisando as estudantes mulheres, de forma geral, estas apresentaram uma média inferior à masculina quanto a Lócus de Controle Interno (LCI), apesar de ser o único Lócus com pontuação alta e considerável. Lócus de Controle Outros Poderosos (LCP) e Lócus de Controle Acaso (LCC) tiveram pontuações de nível baixo, no entanto, pode ser identificado que as mulheres, diferente dos homens, atribuem primeiramente as consequências da vida ao acaso antes de indicar aos outros poderosos, o que determina uma diferença, no grupo investigado, entre os sexos masculino e feminino quanto à determinação de poder de Lócus de Controle.

Quanto à resiliência, homens e mulheres, novamente, apresentaram pontuações diferentes para cada nível analisado, recordando que o nível I representa a capacidade de resolução de ações e valores, que dão sentido à vida, como amizade, realização pessoal, satisfação e significado da vida. O nível II representa independência e determinação e o nível III autoconfiança e capacidade de adaptação a mudanças. Quanto aos estudantes homens os níveis I $(3,92)$ e III $(3,78)$, são considerados altos. Quanto ao nível II de resiliência foi considerado neutra para os homens. Quanto às estudantes mulheres, o mesmo aconteceu; os níveis I e III foram considerados altos e o nível II neutro, com os pontos de 4,01; 3,89 e 3,34 respectivamente. Comparativamente aos homens, as mulheres apresentam todos os níveis de resiliência maiores, indicando que estudantes mulheres são significantemente mais resilientes do que estudantes homens. Logo, as mulheres possuem uma capacidade de superação melhor que a dos homens, mesmo vivenciando situações similares de adversidades (Minello \& Scherer, 2014).

Com os níveis I e III mais altos, subentende-se que as estudantes mulheres são mais realizadas e satisfeitas com suas vidas, tem maior autoconfiança e se adaptam melhor do que os homens em eventuais mudanças que possam acontecer no decorrer dos anos que estão na graduação. Esses achados também determinam que estudantes homens são resilientes, no entanto, com níveis mais elevados para os fatores como a resolução de ações, a realização pessoal, amizades, autoconfiança e adaptação a mudanças.

A Tabela 4 apresenta as estatísticas descritivas quanto as subdivisões de Lócus de Controle e resiliência.

Tabela 4

Subdimensões de Lócus de Controle e Características de Resiliência

\begin{tabular}{ccccc}
\hline & \multicolumn{5}{c}{ Lócus de Controle } & Mesvio-Padrão \\
\hline Variáveis & Mínimo & Máximo & Média & 0,440378 \\
\hline LCI & 1,000 & 4,750 & 3,654 & 0,569004 \\
\hline LCP & 1,000 & 4,875 & 2,424 & 0,578705 \\
\hline LCC & 1,000 & 4,875 & 2,312 & 0,432413 \\
\hline RFI & 1,000 & Resiliência & & 0,44449 \\
\hline RFII & 1,000 & 5,000 & 3,983 & 0,487784 \\
\hline RFIII & 1,000 & 4,667 & 3,315 & 3,854 \\
\hline
\end{tabular}

Fonte: dados da Pesquisa 
Ao analisar as subdimensões de Lócus de Controle especificamente, observa-se pela Tabela 2 que as médias apresentadas apontam que o LCI, é o lócus que melhor representa os respondentes da pesquisa por apresentar a única média com nível alto. Sendo que a amostra de pesquisa é caracterizada por pessoas que atribuem para si a responsabilidade pelo que lhes acontece, sentem-se responsáveis pelo controle da maior parte das situações que enfrentam e acreditam que podem interferir nos resultados destas situações (Dela Coleta, 1987; Callado, Gomes \& Tavares, 2006). Enquanto isso o LCP e LCC apresentaram níveis baixos, não sendo tão considerados pelos estudantes pesquisados.

Quanto à resiliência, os níveis I e III representaram níveis altos e o nível II nível neutro, o que representa que em geral os estudantes de Ciências Contábeis do Brasil são autoconfiantes e têm um nível de satisfação inerentes a estes, que faz com que enfrentem as adversidades com mais perseverança. Isso significa que a amostra é caracterizada por indivíduos que dão sentido à vida, à amizade, à realização pessoal, à satisfação, à autoconfiança e à adaptação a mudanças, tendo em menor escala a ideia de independência e determinação (Pesce et. al, 2005).

$\mathrm{Na}$ Tabela 5 são apresentados os testes t entre o Lócus de Controle, resiliência e sexo, quanto as respostas apontadas pelos respondentes da pesquisa, conforme representado a seguir.

Tabela 5

Teste t entre Lócus de Controle, Resiliência e Sexo

\begin{tabular}{|c|c|c|c|c|c|}
\hline \multicolumn{6}{|c|}{ Teste $\mathbf{t}$} \\
\hline Dados & Grupo & Qnt. & Média & $\mathrm{T}$ & Sig. \\
\hline \multirow{2}{*}{$\mathrm{LCl}$} & 0 & 142 & 3,664 & \multirow{2}{*}{0,311} & \multirow{2}{*}{0,756} \\
\hline & 1 & 307 & 3,650 & & \\
\hline \multirow{2}{*}{ LCC } & 0 & 142 & 2,391 & \multirow{2}{*}{$-0,711$} & \multirow{2}{*}{0,442} \\
\hline & 1 & 307 & 2,440 & & \\
\hline \multirow{2}{*}{ LCP } & 0 & 142 & 2,421 & \multirow{2}{*}{2,740} & \multirow{2}{*}{$0,006 *$} \\
\hline & 1 & 307 & 2,261 & & \\
\hline \multirow{2}{*}{ RFI } & 0 & 142 & 3,926 & \multirow{2}{*}{$-1,930$} & \multirow{2}{*}{$0,054 * * *$} \\
\hline & 1 & 307 & 4,010 & & \\
\hline \multirow{2}{*}{ RFII } & 0 & 142 & 3,257 & \multirow{2}{*}{$-2,197$} & \multirow{2}{*}{$0,029 * *$} \\
\hline & 1 & 307 & 3,341 & & \\
\hline \multirow{2}{*}{ RFIII } & 0 & 142 & 3,780 & \multirow{2}{*}{$-1,877$} & \multirow{2}{*}{$0,061 * * *$} \\
\hline & 1 & 307 & 3,889 & & \\
\hline
\end{tabular}

*. A relação é significativa no nível 0,01 (2 extremidades).

**. A relação é significativa no nível 0,05 (2 extremidades).

***. A relação é significativa no nível 0,10 (2 extremidades).

Legenda: 0 para masculino; 1 para feminino; RFI: Resiliência Fator I (ações e valores); RFII: Resiliência Fator II (independência e determinação e autoconfiança); RFIII: Resiliência Fator III (capacidade de adaptação às mudanças); LCI: Lócus de Controle Interno; LCC: Lócus de Controle ao Acaso; LCP: Lócus de Controle Poderosos;

Fonte: dados da Pesquisa

Quanto ao teste $t$, este determina a diferença encontrada nos grupos estudados. Ao analisar o sexo identifica-se que este foi estatisticamente diferente $(0,006)$ para o grupo de Lócus de Controle dos Poderosos (LCP), determinando que o grupo 0 que se refere aos estudantes homens é superior ao das mulheres, ou seja, homens acreditam mais que os poderosos, ou seja, pessoas mais importantes que ele podem ser responsáveis das consequências da sua vida do que as mulheres. Deste modo, tem-se que os homens manifestam mais emoções, sofrem mais influência afetiva, não assumem responsabilidade direta sobre os objetivos e são mais passíveis de influência persuasiva (Dela Coleta, 1982). 
Quanto à resiliência, quando analisado o teste $\mathrm{T}$ em relação ao sexo, foi identificado que todos os três níveis foram estatisticamente significantes, sendo que o Nível I e o Nível II a 5\% e o Nível 3 a 10\%, com os valores 0,$054 ; 0,029$ e 0,061 , respectivamente. Com estes resultados, é possível afirmar que em todos os grupos homens e mulheres apresentam níveis de resiliência diferentes e, em todos os casos, as mulheres foram mais resilientes do que os homens.

Esses achados ainda determinam que, por serem mais resilientes, as estudantes mulheres conseguem lidar melhor com pressões e problemas decorrentes do curso que estão realizando, fazendo com que permaneçam na graduação e não desistindo frente às dificuldades apresentadas pela graduação em Ciências Contábeis. Assim sendo, tem-se que independente da influência exercida pelo ambiente para com o indivíduo, as mulheres possuem uma maior facilidade e capacidade de adaptação à difíceis situações. Logo, o resultado desta pesquisa corrobora Yunes e Szymanski, (2001) e Minello e Scherer (2014) por encontrar forte resiliência nos achados. Na Tabela 6, são apresentados os testes ANOVA entre o Lócus de Controle, resiliência e variável social denominado estado civil.

Tabela 6

Teste ANOVA entre Lócus, Resiliência e Estado Civil

\begin{tabular}{|c|c|c|c|c|c|}
\hline \multicolumn{6}{|c|}{ ANOVA } \\
\hline & & Df & Quadrado Médio & $\mathrm{F}$ & Sig. \\
\hline \multirow{2}{*}{$\mathrm{LCl}$} & Entre Grupos & 2 & 0,057 & \multirow{2}{*}{0,293} & \multirow{2}{*}{0,747} \\
\hline & Nos grupos & 446 & 0,195 & & \\
\hline \multirow{2}{*}{ LCC } & Entre Grupos & 2 & 2,089 & \multirow{2}{*}{6,613} & \multirow{2}{*}{0,001} \\
\hline & Nos grupos & 446 & 0,316 & & \\
\hline \multirow{2}{*}{ LCP } & Entre Grupos & 2 & 1,949 & \multirow{2}{*}{5,949} & \multirow{2}{*}{0,003} \\
\hline & Nos grupos & 446 & 0,328 & & \\
\hline \multirow{2}{*}{ RFI } & Entre Grupos & 2 & 0,006 & \multirow{2}{*}{0,033} & \multirow{2}{*}{0,968} \\
\hline & Nos grupos & 446 & 0,188 & & \\
\hline \multirow{2}{*}{ RFII } & Entre Grupos & 2 & 0,135 & \multirow{2}{*}{0,565} & \multirow{2}{*}{0,569} \\
\hline & Nos grupos & 446 & 0,238 & & \\
\hline \multirow{2}{*}{ RFIII } & Entre Grupos & 2 & 0,107 & \multirow{2}{*}{0,542} & \multirow{2}{*}{0,582} \\
\hline & Nos grupos & 446 & 0,198 & & \\
\hline & Dependente & (I) & (J) & Diferença média (I-J) & Sig. \\
\hline \multirow{6}{*}{\multicolumn{2}{|c|}{ LCC }} & \multirow[t]{2}{*}{0} & 1 & 0,186283 & 0,003 \\
\hline & & & 2 & 0,192 & 0,192 \\
\hline & & \multirow{2}{*}{1} & 0 & 0,003 & 0,003 \\
\hline & & & 2 & 0,897 & 0,897 \\
\hline & & \multirow[b]{2}{*}{2} & 0 & 0,192 & 0,192 \\
\hline & & & 1 & 0,897 & 0,897 \\
\hline & \multirow{6}{*}{ LCP } & \multirow{2}{*}{0} & 1 & 0,161232 & 0,015 \\
\hline & & & 2 & 0,063 & 0,063 \\
\hline & & \multirow{2}{*}{1} & 0 & 0,015 & 0,015 \\
\hline & & & 2 & 0,482 & 0,482 \\
\hline & & \multirow{2}{*}{2} & 0 & 0,063 & 0,063 \\
\hline & & & 1 & 0,482 & 0,482 \\
\hline
\end{tabular}

Legenda: 0 - solteiro; 1- Casado/ Companheiro(a) 2- separado (a)/divorciado (a) 3- viúvo (a)

Fonte: dados da Pesquisa 
Quanto à Tabela 6, o Teste ANOVA foi realizado considerando a variável social estado civil, em relação aos grupos de Lócus de Controle, tanto o Lócus de Controle Externo (LCC), como o Lócus dos Poderosos (LCP) foram estatisticamente significantes, determinando diferença estatística de Lócus de Controle dependendo do estado civil do estudante de Contabilidade. Quanto à resiliência, não houve nenhuma diferença entre os grupos estatisticamente, o que determina que os estados civis não são responsáveis pela diferença dos grupos. Tem-se deste modo que as diferenças no estado civil não alteram a capacidade de adaptação dos estudantes de Contabilidade, indicando que os estudantes não possuem maior ou menor motivação para enfrentar as dificuldades do ambiente, tendo um companheiro ou não.

Ainda quanto às diferenças no Lócus de Controle, para identificar qual ou quais dos grupos de estado civil se diferenciam em relação ao grupo dos externos e poderosos, foi realizado o teste de Sheffer. Com base nos resultados do teste demonstrados também na Tabela 6, são possíveis algumas constatações. Ao observar o Lócus de Controle Externo, o grupo 0 que se refere aos solteiros foi estatisticamente diferente do grupo 1 que se refere aos casados ou com companheiros. Esses resultados indicam que o Lócus de Controle Externo (LCC) é mais encontrado para os estudantes solteiros.

Algumas pesquisas determinam que indivíduos com Lócus de Controle Externo, os quais de fato não acreditam que podem controlar aspectos importantes de seus ambientes, são mais propensos a considerar o ambiente de trabalho ameaçador e estressante (Spector \& O'Connell, 1994; Callado, Gomes \& Tavares, 2006). Esses achados são importantes por compreender que estudantes solteiros podem considerar o ambiente da IES estressante e não conseguir lidar com eventos contrários decorrentes do percurso da graduação, fazendo por vezes desistir do curso.

Quanto ao grupo de Lócus de Controle dos Poderosos (LCP), quando realizado o teste de Sheffer, foram identificados dois grupos estatisticamente diferentes tanto dos solteiros para os casados ou com companheiros, como dos solteiros para os separados ou divorciados. Os solteiros nos dois casos são os que mais determinam as consequências da sua vida, dependendo de pessoas poderosas, que, segundo Levenson (1973), são pessoas que acreditam no poder de outras pessoas, mas não acreditam no azar e nem em si próprios. De acordo, tem-se que os estudantes solteiros determinam de forma mais forte os acontecimentos de sua vida a pessoas poderosas; infere-se que tal fato pode ser decorrente de pessoas solteiras no ambiente do ensino superior serem em suma dependentes de alguém, como pais, responsáveis, parentes, namorados (as), colegas de quarto, entre outros e, portanto, não atribuírem de forma primeira as consequências somente a si próprio e, sim, pensarem que terceiros influenciaram os acontecimentos.

$\mathrm{Na}$ Tabela 7 são apresentados os testes ANOVA entre o Lócus de Controle, resiliência e instituição de ensino superior. 
Tabela 7

Teste ANOVA entre Lócus, Resiliência e IES

\begin{tabular}{|c|c|c|c|c|c|}
\hline \multicolumn{6}{|c|}{ ANOVA } \\
\hline & & Df & Quadrado Médio & $\mathrm{F}$ & Sig. \\
\hline \multirow{2}{*}{$\mathrm{LCl}$} & Entre Grupos & 2 & 0,218 & \multirow{2}{*}{1,127} & \multirow{2}{*}{0,325} \\
\hline & Nos grupos & 446 & 0,194 & & \\
\hline \multirow{2}{*}{ LCC } & Entre Grupos & 2 & 0,933 & \multirow{2}{*}{2,907} & \multirow{2}{*}{0,056} \\
\hline & Nos grupos & 446 & 0,321 & & \\
\hline \multirow{2}{*}{ LCP } & Entre Grupos & 2 & 0,602 & \multirow{2}{*}{0,602} & \multirow{2}{*}{0,166} \\
\hline & Nos grupos & 446 & 0,334 & & \\
\hline \multirow{2}{*}{ RFI } & Entre Grupos & 2 & 0,660 & \multirow{2}{*}{0,660} & \multirow{2}{*}{0,029} \\
\hline & Nos grupos & 446 & 0,185 & & \\
\hline \multirow{2}{*}{ RFII } & Entre Grupos & 2 & 0,585 & \multirow{2}{*}{0,585} & \multirow{2}{*}{0,085} \\
\hline & Nos grupos & 446 & 0,236 & & \\
\hline \multirow{2}{*}{ RFIII } & Entre Grupos & 2 & 1,037 & \multirow{2}{*}{1,037} & \multirow{2}{*}{0,005} \\
\hline & Nos grupos & 446 & 0,194 & & \\
\hline & Dependente & (I) & (J) & Diferença média (I-J) & Sig. \\
\hline \multirow{6}{*}{\multicolumn{2}{|c|}{ LCC }} & \multirow{2}{*}{0} & 1 & 0,039620 & 0,828 \\
\hline & & & 2 & 0,533929 & 0,056 \\
\hline & & \multirow{2}{*}{1} & 0 & $-0,039620$ & 0,828 \\
\hline & & & 2 & 0,494309 & 0,075 \\
\hline & & \multirow{2}{*}{2} & 0 & $-0,533929$ & 0,056 \\
\hline & & & 1 & $-0,494309$ & 0,075 \\
\hline \multirow{6}{*}{\multicolumn{2}{|c|}{ RFII }} & \multirow{2}{*}{0} & 1 & $-0,074181$ & 0,334 \\
\hline & & & 2 & 0,431667 & 0,044 \\
\hline & & \multirow{2}{*}{1} & 0 & 0,074181 & 0,334 \\
\hline & & & 2 & 0,505848 & 0,011 \\
\hline & & \multirow{2}{*}{2} & 0 & $-0,431667$ & 0,044 \\
\hline & & & 1 & $-0,505848$ & 0,011 \\
\hline & \multirow{6}{*}{ RFIII } & \multirow{2}{*}{0} & 1 & 0,025029 & 0,903 \\
\hline & & & 2 & 0,422857 & 0,085 \\
\hline & & 1 & 0 & $-0,025029$ & 0,903 \\
\hline & & 1 & 2 & 0,397828 & 0,102 \\
\hline & & $?$ & 0 & $-0,422857$ & 0,085 \\
\hline & & 2 & 1 & $-0,397828$ & 0,102 \\
\hline
\end{tabular}

Legenda: 0 - Pública; 1 - Privada; 2- Pública-Privada

Fonte: dados da Pesquisa

Quanto a Tabela 5, o teste ANOVA foi realizado considerando a variável de IES, se pública, privada ou mista (pública-privada) em relação aos grupos de Lócus de Controle e resiliência. Quanto ao Lócus de Controle, identifica-se que apenas o Lócus de Controle Externo (LCC) foi estatisticamente significante, determinando que para esta variável existem diferenças dependendo de qual IES o estudante pertence. Para tanto, identificou-se que em nível de $5 \%$ o Lócus de Controle justificado por fatores externos (LCC) é maior em IES mistas, pública-privada, do que nas IES públicas. Em cerca de 10\% o resultado semelhante ocorre quando confrontado IES mistas, pública-privada e IES privadas. 
Tem-se assim que estudantes de instituições mistas possuem um maior nível de Lócus de Controle Externo, indicando que estes estudantes atribuem os acontecimentos no seu dia-a-dia a sorte ou terceiros ao invés de a si próprios. Para Dela Coleta (1982) os externalistas expressam mais suas emoções, recebem as ações das pessoas ao seu redor de forma mais afetiva, não se comprometem de forma forte com suas responsabilidades e sofrem maior influência de terceiros.

Quanto à resiliência, o teste ANOVA também determinou diferenças significativas para os níveis II e III. A resiliência de nível II é diferente entre os acadêmicos tanto das instituições públicas como das privadas em relação às IES mistas. Já para a resiliência de nível III, apenas a pública e a mista foram estatisticamente significantes, determinando uma diferença entre os grupos. Esses achados determinam que acadêmicos de IES mistas possuem níveis maiores de resiliência, indicando que os estudantes dessas instituições lidam melhor com situações de adversidades. Infere-se que tal fato ocorra por este estudante estar expostos às dificuldades desses dois tipos de instituições; o ônus financeiro das IES privadas e suposta maior exigência das IES públicas. Estes fatos podem influenciar a resiliência dos estudantes, uma vez que Díaz et al. (2011) afirmam que é a combinação entre a natureza, a quantidade e a intensidade dos fatores de risco o que define o contexto da adversidade necessária para a resiliência.

A Tabela 8 apresenta as regressões realizadas com a resiliência enquanto uma variável geral em relação aos níveis de Lócus de Controle. Inicialmente, pode se observar que os pressupostos para a utilização da regressão foram atendidos, uma vez que os testes comprovam a normalidade dos dados, mesmo que pela grande quantidade de dados a normalidade já possa ser assumida. $\mathrm{O}$ mesmo pode ser comprovado pelos testes Pesarán-Pesarán, ANOVA, Durbin-Watson e VIF, que atendem ao necessário e assumem a homoscedasticidade, linearidade, auto correlação e multicoliaridade dos dados.

Tabela 8

\section{Regressões: Resiliência e Lócus de Controle}

\begin{tabular}{|c|c|c|c|c|c|c|c|}
\hline $\begin{array}{c}\text { Variável } \\
\text { dependente }\end{array}$ & Variável independente & Beta & t-statistic & Sig. & VIF & $\mathbf{R}^{2}$ & $\begin{array}{c}\text { Sig. } \\
\text { modelo }\end{array}$ \\
\hline & $\mathrm{LCl}$ & 0,477 & 11,850 & $0,000 *$ & 1,017 & & \\
\hline \multirow[t]{3}{*}{ RFI } & LCC & 0,013 & 0,311 & 0,756 & 1,805 & 0,255 & 0,000 \\
\hline & LCP & $-0,129$ & $-3,244$ & $0,001 *$ & 1,816 & & \\
\hline & $\mathrm{LCl}$ & 0,336 & 7,522 & $0,000 *$ & 1,017 & & \\
\hline \multirow[t]{3}{*}{ RFII } & LCC & 0,158 & 3,508 & $0,000 *$ & 1,805 & 0,132 & 0,000 \\
\hline & LCP & $-0,115$ & $-2,591$ & $0,010 *$ & 1,816 & & \\
\hline & $\mathrm{LCl}$ & 0,465 & 9,779 & $0,000 *$ & 1,017 & & \\
\hline \multirow[t]{3}{*}{ RFIII } & LCC & 0,091 & 1,895 & $0,059 * \star *$ & 1,805 & 0,182 & 0,000 \\
\hline & LCP & $-0,040$ & $-0,841$ & 0,401 & 1,816 & & \\
\hline & $\mathrm{LCl}$ & 0,440 & 12,580 & $0,000 *$ & 1,017 & & \\
\hline \multirow[t]{2}{*}{ RESIL } & LCC & 0,063 & 1,790 & $0,074 * \star \star$ & 1,805 & 0,269 & 0,000 \\
\hline & LCP & $-0,108$ & $-3,110$ & $0,002^{*}$ & 1,816 & & \\
\hline \multicolumn{8}{|c|}{ Pressupostos da Regressão } \\
\hline \multicolumn{2}{|c|}{ Pressuposto } & \multicolumn{4}{|c|}{ Teste } & \multicolumn{2}{|r|}{ Valor } \\
\hline \multicolumn{2}{|c|}{ Normalidade } & \multicolumn{4}{|c|}{ Kolmogorov-Smirnov } & \multicolumn{2}{|r|}{0,453} \\
\hline \multicolumn{2}{|c|}{ Homoscedasticidade } & \multicolumn{4}{|c|}{ Pesarán-Pesarán } & \multicolumn{2}{|r|}{0,410} \\
\hline \multicolumn{2}{|c|}{ Linearidade } & \multicolumn{4}{|c|}{ ANOVA } & \multicolumn{2}{|r|}{0,000} \\
\hline \multicolumn{2}{|c|}{ AutoCorrelação } & \multicolumn{4}{|c|}{ Durbin-Watson } & \multicolumn{2}{|r|}{1,909} \\
\hline
\end{tabular}

\footnotetext{
*. A relação é significativa no nível 0,01 (2 extremidades).

**. A relação é significativa no nível 0,05 (2 extremidades).

***. A relação é significativa no nível 0,10 (2 extremidades).
}

Legenda: RFI: Resiliência Fator I ; RFII: Resiliência Fator II ; RFIII: Resiliência Fator III ; RESIL: Resiliência Geral; LCI: Lócus de Controle Interno; LCC: Lócus de Controle ao Acaso; LCP: Lócus de Controle Poderosos; 
De acordo com a Tabela 8, quando testada a relação da resiliência Nível I e os 3 níveis de Lócus de Controle Interno, Externo e dos Poderosos, os resultados da regressão sugerem que o Lócus de Controle Interno (LCI) e o que se refere aos Poderosos (LCP) foram estatisticamente significantes, determinando que estes formatos de Lócus de Controle explicam o Nível I de resiliência, segundo esta amostra de estudantes respondentes. Quanto ao Nível II de resiliência, todos os lócus foram estatisticamente significantes, determinando que todas as formas de Lócus de Controle identificados nestes estudantes contribuem para determinar o quão resilientes eles são. Quanto ao Nível III de resiliência, tanto o Lócus de Controle Interno (LCI) como o Lócus de Controle Poderosos (LCP) explicam este nível.

Quando analisada a resiliência de forma geral, pode-se dizer que esta é explicada pelos Lócus de Controle encontrado em cada estudante, independente do que estes consideram, se o Lócus Interno, Externo ou os Poderosos. Esses achados são importantes visto que aspectos comportamentais impactam os trabalhos desenvolvidos pelas pessoas em suas respectivas áreas, bem como o apontado por Rotter (1966) sobre considerar a interação do sujeito com o ambiente, as variáveis de personalidade e as características individuais, considerando que a identificação destas percepções permite a identificação de grupos e de características que representam sinais de atenção para as instituições de modo que pode inibir sofrimento durante o processo de formação acadêmica e garantir a melhora como profissional no futuro.

Logo, os achados da pesquisa indicam que o Lócus de Controle, que compreende as características dos sujeitos e se estas impactam a resistência à coerção, influenciam a capacidade de aceitar desafios e a propensão de persistência nos esforços para obtenção de resultados (Rodrigues, 2007) e explica a resiliência, que é entendida como o conjunto de processos sociais e intrapsíquicos que possibilitam o desenvolvimento de uma vida sadia, mesmo vivendo em um ambiente não sadio (Pesce et al., 2004). Particularmente, no âmbito educacional, estudos como este são importantes considerando a necessidade de equilibrar as demandas de habilidades sociais, acadêmicas e pessoais e superar as adversidades para garantir sucesso em todas as esferas existentes na vida de um acadêmico (Ruter,1987, Díaz, Giraldo, \& Buitrago, 2011).

\subsection{Discussão dos resultados}

Analisando individualmente cada variável, foi possível identificar um perfil para os estudantes de Contabilidade respondentes da pesquisa. De forma particular, foi possível identificar que homens e mulheres apresentaram um nível de Lócus de Controle Interno alto. Sendo assim, pode-se dizer que estes acadêmicos aceitam mais desafios e são mais esforçados no atingimento das metas e objetivos, como é o caso de concluir a graduação, mesmo com dificuldades no decorrer do curso. Por estes serem também mais resistentes à coerção, possivelmente são os acadêmicos que não trocaram de curso.

Mesmo que não pontuando de forma significativa como o Lócus de Controle Interno, os Lócus de Controle ao acaso e o Lócus de Controle aos Poderosos, tiveram pontuações diferentes para homens e mulheres. O que pode ser identificado com essas diferenças é que as mulheres primeiro atribuem a responsabilidade dos eventos da sua vida a fatores externos, como a sorte ou Deus, enquanto os homens, primeiro atribuem a outros poderosos, ou seja, pessoas que são mais importantes que ele próprio, atribuindo a esses a responsabilidade pela determinação dos seus resultados. No ambiente da graduação, figuraria como a mulher acreditando no azar, enquanto os homens acreditando que uma nota baixa seria consequência do professor, por exemplo.

Quando analisada a resiliência, que neste estudo foi mensurada por fatores, identificou-se que homens e mulheres apresentaram níveis altos para o Fator I e para o Fator III; igualmente os resultados foram neutros para o Fator II. Esses resultados determinam que os estudantes de Contabilidade apresentam altos níveis de resiliência, especialmente as mulheres que pontuaram em maior nível que os homens em todos os fatores. Como já identificado por pesquisas anteriores, existe, sim, diferença entre os sexos. Os Fatores I e III indicam que na vida de cada um estão presentes valores como amizades, satisfação e realização pessoal, bem como autoconfiança e capacidade de adaptação frente a mudanças, que, no caso da 
graduação de Ciências Contábeis, poderiam estar relacionadas às frequentes mudanças de legislação, o que faz com que o aluno precise estar sempre atualizado e buscando novos conhecimentos; assim precisa estar amparado de confiança em si mesmo para persistir e ser o profissional que almeja.

Quando foi analisada na seção anterior a característica social de estado civil com o Lócus de Controle e resiliência dos estudantes, foi encontrado que o Lócus de Controle é diferente para os estudantes, dependendo do estado civil, mas não diferente estatisticamente quanto à resiliência. Com os testes realizados, foi possível identificar que o Lócus de Controle Externo, que se refere ao acaso, é maior para os estudantes solteiros. Esses achados podem ser justificados, visto que os estudantes casados costumam ter maiores responsabilidades e sentir-se deste modo os maiores responsáveis por suas escolhas de vida, visto que já precisam tomar decisões diariamente dentro do seu ambiente familiar, fazendo com que sejam igualmente mais persistentes no curso.

O Lócus de Controle dos Poderosos também foi estatisticamente diferente dos solteiros para os casados e dos solteiros para os viúvos. Os solteiros novamente são os que atribuem às consequências de sua vida às pessoas poderosas. Os achados determinam que de forma geral os solteiros são mais passiveis de influência persuasiva e sofrem mais de influências afetivas, ou seja, podem ser aqueles mais dispostos a desistir por se sentirem pressionados por outra pessoa, podendo ser os pais ou amigos. Conforme discutido na seção anterior, podem sentir mais a pressão do ambiente, e não saberem lidar com o estresse.

Quanto às variáveis de IES, pública, privada e mista (pública-privada) quanto ao Lócus de Controle, foram encontradas diferenças estatísticas quando se referia ao Lócus de Controle ao acaso. Os achados apontam que estudantes que pertencem a instituições de ensino com a característica de mistas são os que mais apresentaram Lócus de Controle ao acaso, não tomando posse de suas responsabilidades sobre o que lhe acontecem. Quanto à resiliência os achados são semelhantes estudantes de instituições mistas possuem níveis de resiliência diferentes daqueles estudantes de instituições públicas ou privadas.

Foram realizadas ainda regressões de modo a identificar se fatores de Lócus de Controle explicavam a resiliência dos estudantes pesquisados. Com as regressões analisando os fatores separadamente, foi possível determinar que o nível de resiliência tipo I que se refere às coisas que dão sentido à vida são constituídos por indivíduos que possuem Lócus de Controle Interno e parte de Lócus de Controle em Poderosos. No nível III, os achados se repetem e no nível II todos os formatos de lócus foram estatisticamente significantes, fazendo com que se conclua que o nível de resiliência é determinado pelo Lócus de Controle dos indivíduos, independente se Interno ou Externo. Assim, tem-se que as hipóteses desenvolvidas no estudo foram aceitas e estão expostas na Tabela 9.

Tabela 9

\section{Aceitação das Hipóteses}

\begin{tabular}{lc}
\hline \multicolumn{1}{c}{ Hipótese } & Situação \\
\hline H1: A resiliência de estudantes contábeis possui relação com o lócus de controle. & Não rejeita-se. \\
\hline $\begin{array}{l}\text { H2: As características sociais discriminam a resiliência e o lócus de controle dos } \\
\text { estudantes de contabilidade. }\end{array}$ & Não rejeita-se. \\
\hline
\end{tabular}

Fonte: dados da pesquisa.

Por fim, têm-se achados inéditos, que incitam novas pesquisas que compreendam a fundo estes ambientes estudados e que podem indicar possibilidades de pesquisas que auxiliem responsáveis, professores ou autoridades no treinamento de habilidades pessoais e de autoconhecimento, de modo que o indivíduo não se traumatize, seja mais resiliente e alcance maiores níveis de Lócus de Controle Interno frente às dificuldades encontradas durante a realização do curso de Ciências Contábeis. 


\section{Considerações Finais}

A presente pesquisa teve por objetivo analisar a relação do Lócus de Controle Interno e Externo com a resiliência, de acordo com as características sociais dos estudantes de Contabilidade. Desta forma, a pesquisa caracteriza-se como descritiva, survey e quantitativa. Para a realização deste estudo, foi encaminhado a estudantes de Ciências Contábeis um questionário composto de três seções; a primeira referente a dados demográficos - nesta pesquisa denominados "dados sociais"; a segunda relativa a Lócus de Controle; e por fim, a terceira sobre resiliência. Com os respondentes, a pesquisa contou com uma amostra 449 estudantes.

Os resultados apontaram que existem diferenças entre homens e mulheres frente aos Lócus de Controle e resiliência. Mulheres possuem um nível um pouco mais baixo de Lócus de Controle Interno comparativamente aos homens, apesar de ambos terem altos níveis. Quanto à resiliência as mulheres são as que possuem os maiores níveis em todos os níveis; I, II e III. As diferenças encontradas também se estenderam para o estado civil, sendo os solteiros os mais diferentes em relação aos estados civis encontrados na amostra. Quanto às IES, foi identificado que os estudantes de instituições mistas (pública-privada) são os que mais apresentaram Lócus de Controle ao Acaso, não tomando posse de suas responsabilidades sobre o que lhe acontecem.

Tendo em vista os resultados encontrados e as discussões apresentadas por este trabalho, conclui-se que estudantes de Contabilidade, de forma geral têm altos níveis de resiliência, bem como de Lócus de Controle Interno, o que faz com que tenham um perfil de pessoas determinadas, autoconfiantes e perseverantes frente às dificuldades oferecidas durante o curso de graduação em Ciências Contábeis. Destaca-se ainda a relação encontrada entre a resiliência e o Lócus de Controle, estes comprovados na regressão, uma vez que foi encontrado que o Lócus de Controle Interno e o Acaso aumentam a resiliência dos estudantes e o Lócus de Controle outros Poderosos diminui a resiliência. Os achados também são importantes no cenário nacional por representar uma perspectiva de pesquisa pouco realizada quanto Contabilidade comportamental.

Como contribuição teórica, destacam-se os achados da pesquisa quanto aos estudantes de Contabilidade, potenciais futuros realizadores das demonstrações contábeis e a investigação na área de comportamento humano, trazendo a interdisciplinaridade ao estudo entre psicologia e ciências sociais aplicadas. Este estudo também tem como frente a abertura e o estímulo a novas pesquisas que compreendam o ambiente e as relações entre variáveis sociais e comportamentais, estabelecendo caminho e oportunidade para estudos futuros.

Como limitação para este estudo, destaca-se a escolha das escalas, segundo a interpretação dos autores, por ser uma escolha intencional. Para tanto, sugerem-se novos estudos como este ou utilizando outras variáveis, para melhor compreender as variáveis que podem de fato relacionar-se com fatores comportamentais dos indivíduos. Sugere-se, ainda, a realização de outros estudos com outros grupos pertencentes a Contabilidade, de modo que se possa comparar os achados com os resultados obtidos a partir desta pesquisa.

\section{Referências}

Angst, R. (2013). Habilidades sociais e resiliência em acadêmicos de licenciaturas. Dissertação de Mestrado, Universidade Federal do Paraná, Curitiba, PR, Brasil.

Barreira, D. D., \& Nakamura, A. P. (2006). Resiliência e a auto-eficácia percebida: articulação entre conceitos. Aletheia, 23, pp. 75-80.

Callado, M. C., Gomes, J. A. \& Tavares, L. E. (2006). Lócus de controle interno: uma característica de empreendedores. Revista de Administração Mackenzie, 11(2), pp. 168-188.

Calvo, J. C. A. \& García, G. M. (2010). Established Business Owners'success: Influencing Factors. Journal of developmental entrepreneurship, 15(03), pp. 263-286.

Dela Coleta, M. F. (1987). Escala multidimensional de locus de controle de Levenson. Arquivos Brasileiros de Psicologia, 39(2), pp. 79-97. 
Cowen, E. L., Wyman, P. A. \& Work, W. C. (1996). Resilience in highly stressed urban children: concepts and findings. Bulletin of the New York Academy of Medicine, 73(2), p. 267.

Cunha, J., Nascimento, E. \& Durso, S. (2014). Razões e influências para a evasão universitária nos cursos de Ciências Contábeis de instituições públicas federais da região Sudeste. Congresso USP de Controladoria e Contabilidade, São Paulo, SP, Brasil, 14.

Damascena, L. G., França, R. D. \& Silva, J. D. G. (2016). Relação entre locus de controle e resiliência: um estudo com profissionais contábeis. Revista Contemporânea de Contabilidade, 13(29), pp. 69-90.

Dela Coleta, J. A. (1982). Atribuição de causalidade: teoria e pesquisa. FGV-Instituto de Documentação, Editora da Fundação Getúlio Vargas.

Díaz, S. C. P., Giraldo, A. F. R. \& Buitrago, H. C. (2011). Factores resilientes asociados al rendimiento académico en estudiantes pertenecientes a la Universidad de Sucre (Colombia). Psicología desde el Caribe, pp. 196-219.

Farag, M. S. \& Elias, R. Z. (2016). The relationship between accounting students' personality, professional skepticism and anticipatory socialization. Accounting Education, 25(2), pp. 124-138. doi: http:// dx.doi.org/10.1080/09639284.2015.1118639.

Fávero, L. P., Belfiore, P., Silva, F. L. \& Chan, B. L. (2009). Análise de Dados: Modelagem Multivariada para tomada de Decisões. Rio de Janeiro, Elsevier.

Fortes, T. F. R., Portuguez, M. W. \& Argimon, I. I. D. L. (2009). A resiliência em idosos e sua relação com variáveis sociodemográficas e funções cognitivas. Estud. psicol.(Campinas), 26(4), pp. 455-463. doi: http://dx.doi.org/10.1590/S0103-166X2009000400006.

Grotberg, E. H.(Ed.). (2003). Resilience for today: Gaining strength from adversity. Greenwood Publishing Group.

Hair, J. F., Black, W. C., Babin, B. J., Anderson, R. E. \& Tatham, R. L. (2009). Análise multivariada de dados. Bookman Editora.

Hasin, H., \& Omar, N. (2007). An empirical study on job satisfaction, job-related stress and intention to leave among audit staff in public accounting firms in Melaka. Journal of Financial Reporting and Accounting, 5(1), pp. 21-39. doi: 10.1108/19852510780001575

Infante, F. (2005). A resiliência como processo: uma revisão da literatura recente. Resiliência: descobrindo as próprias fortalezas, pp. 23-38.

Lefcourt, H. M. (1976). Locus of control and the response to aversive events. Canadian Psychological Review/Psychologie Canadienne, 17(3), p. 202. doi http://dx.doi.org/10.1037/h0077149;

Levenson, H. (1973). Multidimensional locus of control in psychiatric patients. Journal of consulting and clinical psychology, 41(3), p. 397. doi.apa.org/journals/ccp/41/3/397

Lucena, W. G. L., Fernandes, M. S. A. \& Silva, J. D. G. (2011). A contabilidade comportamental e os efeitos cognitivos no processo decisório: uma amostra com operadores da contabilidade. Revista Universo Contábil, $7(3)$.

MacDonald, J. R. (1973). Theory of space-charge polarization and electrode-discharge effects. The Journal of Chemical Physics, 58(11), pp. 4982-5001. doi:

https://aip.scitation.org/doi/10.1063/1.1679086

Maciel, C. D. O. \& Camargo, C. (2010). Lócus de controle, comportamento empreendedor e desempenho de pequenas empresas. RAM. Revista de Administração Mackenzie, 11(2), pp. 168-188. doi: http:// dx.doi.org/10.1590/S1678-69712010000200008. 
Magalhães, M. D. O. (2005). Personalidades vocacionais e desenvolvimento na vida adulta: generatividade e carreira profissional. Dissertação de pós-graduação na Universidade Federal do Rio Grande do Sul, Porto Alegre, RS, Brasil

Minello, I. F. \& Scherer, I. B. (2014). Características resilientes do empreendedor associadas ao insucesso empresarial. Revista de Ciências da Administração, 16(38). doi: https://doi.org/10.5007/2175$-8077.2014 \mathrm{v} 16 \mathrm{n} 38 \mathrm{p} 228$

Oliveira, M. A., Reis, V. L., Zanelato, L. S. \& Neme, C. M. B. (2008). Resiliência: análise das publicações no período de 2000 a 2006. Psicologia ciência e profissão, 28(4). doi: http://dx.doi.org/10.1590/S141498932008000400008

Pesce, R. P., Assis, S. G., Avanci, J. Q., Santos, N. C., Malaquias, J. V. \& Carvalhaes, R. (2005). Adaptação transcultural, confiabilidade e validade da escala de resiliência. Cadernos de Saúde pública, 21(2), pp. 436-448.

Pesce, R. P., Assis, S. G., Santos, N. \& Oliveira, R. D. (2004). Risco e proteção: em busca de um equilíbrio promotor de resiliência. Psicologia: teoria e pesquisa, 20(2), pp. 135-143.

Rodrigues, D. M. (2007). Os aspectos cognitivos da qualidade de vida: um estudo entre as variáveis do lócus de controle e as do bem-estar subjetivo (Doctoral dissertation). Tese de Doutorado. Universidade Federal do Rio de Janeiro, Rio de Janeiro, RJ, Brasil.

Rogge, J. F. N. \& Lourenço, M. L. (2015). A resiliência humana no ambiente acadêmico de cursos stricto sensu. Revista de Administração IMED, 5(3), pp. 291-301.

Rotter, J. B. (1966). Generalized expectancies for internal versus external control of reinforcement. Psychological monographs: General and applied, 80(1), p. 1. doi http://dx.doi.org/10.1037/h0092976

Rutter, M. (1987). Psychosocial resilience and protective mechanisms. American journal of orthopsychiatry, 57(3), p. 316. doi: https://doi.org/10.1111/j.1939-0025.1987.tb03541.x.

Rutter, M. (2012). Resiliência como um conceito dinâmico. Development and Psychopathology. Cambridge University Press, 24, pp. 335-344. doi: 10.1017/S0954579412000028,

Savoia, M. G. (1999). Escalas de eventos vitais e de estratégias de enfrentamento (coping). Revista de Psiquiatria Clínica, 26(2), pp. 57-67.

Selye, H. (1974). Stress without distress. New York, pp. 26-39.

Siegel, G. \& Ramanauskas-Marconi, H. (1989). Behavioral accounting. South-Western Publishing Company.

Spector, P. E. \& O'Connell, B. J. (1994). The contribution of personality traits, negative affectivity, locus of control and Type A to the subsequent reports of job stressors and job strains. Journal of Occupational and Organizational Psychology, 67(1), pp. 1-12. doi: https://doi.org/10.1111/j.2044-8325.1994.tb00545.x

Tamayo, Á. (2012). Validade fatorial da escala Levenson de locus de controle. Psicologia: Teoria e Pesquisa, 5(1), 111-122.

Wagnild, G., \& Young, H. (1993). Development and psychometric. Journal of nursing measurement, 1(2), pp. 165-17847. doi: 10.4236/psych.2018.97107

Yunes, M. A. M. (2003). Psicologia positiva e resiliência: o foco no indivíduo e na família.

Yunes, M. A. M., \& Szymanski, H. (2001). Resiliência: noção, conceitos afins e considerações críticas. Resiliência e educação, 2, pp. 13-43. 